\title{
An Empirical Research on Influencing Factors of New Energy Automobile Mass Consumers Purchase: Sample Data from China
}

\author{
Yiyang Tang \\ Zhejiang Traffic Technician College, Zhejiang Jinhua, 321015 \\ elizatang@163.com
}

Keywords: New energy vehicle; Purchasing; Influencing factors; Mass Consumer

\begin{abstract}
Mass consumers are important drivers of the development of the new energy automotive industry, which directly affects the sales of new energy vehicles. From the four dimensions of personal attributes, product attributes, policy attributes and social attributes, the questionnaire of influencing factors for consumers purchasing new energy vehicles is made, the sample data is obtained, and the survey results are analyzed according to the sample data to provide suggestions for the development of new energy automotive industry.
\end{abstract}

\section{Introduction}

On March 5, 2018, at the 13th National People's Congress meeting held in Beijing, Premier Li Keqiang's "Government Work Report" clearly stated that the preferential policy for new energy vehicle purchase tax was extended for another three years. This is undoubtedly another strong agent for the new energy automobile industry. In recent years, with the strong support of the state, the new energy automobile industry has developed rapidly. According to public data, in 2017, the sales volume of new energy vehicles in China has reached 777,000, an increase of 53.25\% over the same period of last year. Among them, passenger cars have increasingly become the main force of promotion, with sales reaching 556,400, accounting for $71.61 \%$. Figure 1 and Figure 2 show the sales volume and growth rate of new energy vehicles and new energy passenger vehicles in the first quarter of 2012-2018.

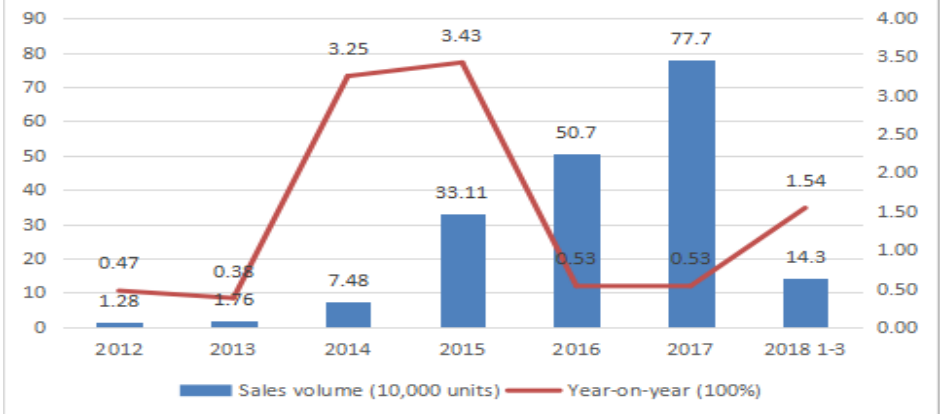

Figure 1 Sales and growth of new energy vehicles in the first quarter of 2012-2018 


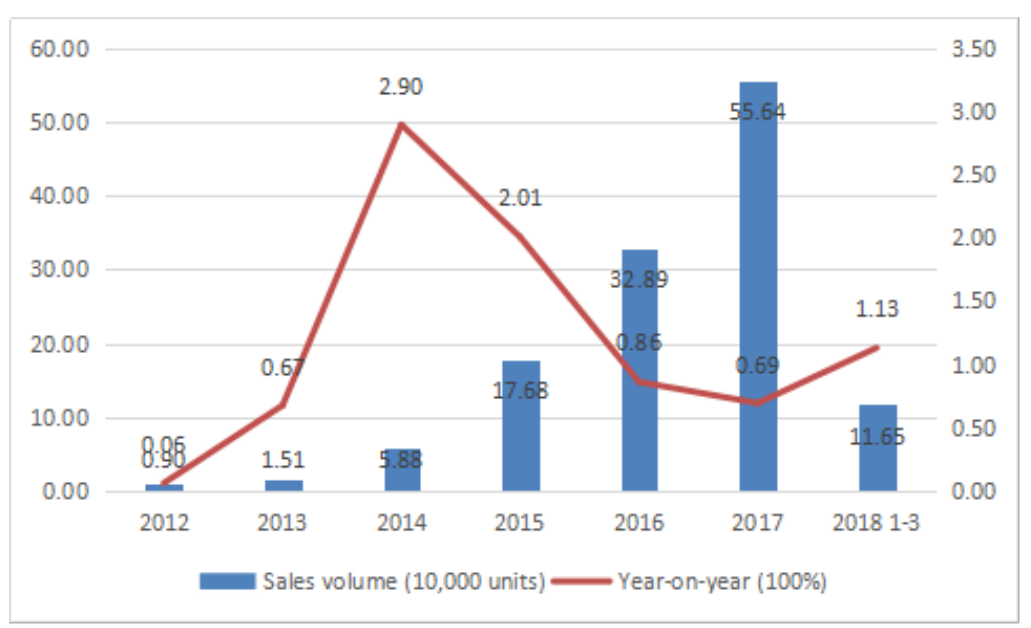

Figure 2 Sales and growth of new energy vehicles in the first quarter of 2012-2018

With the continued strong support of national policies, domestic and foreign companies are accelerating the production capacity layout and new product launches. The new energy vehicle market is expected to continue to maintain rapid growth. It is estimated that sales will reach 1 million units in 2018 and 1.4 million units in 2019. It is expected to break through 2 million vehicles. Given the bright future of the new energy automobile industry, consumers as the ultimate driving force of the new energy automobile industry, the research on the factors influencing consumer purchase has high theoretical value and economic value.

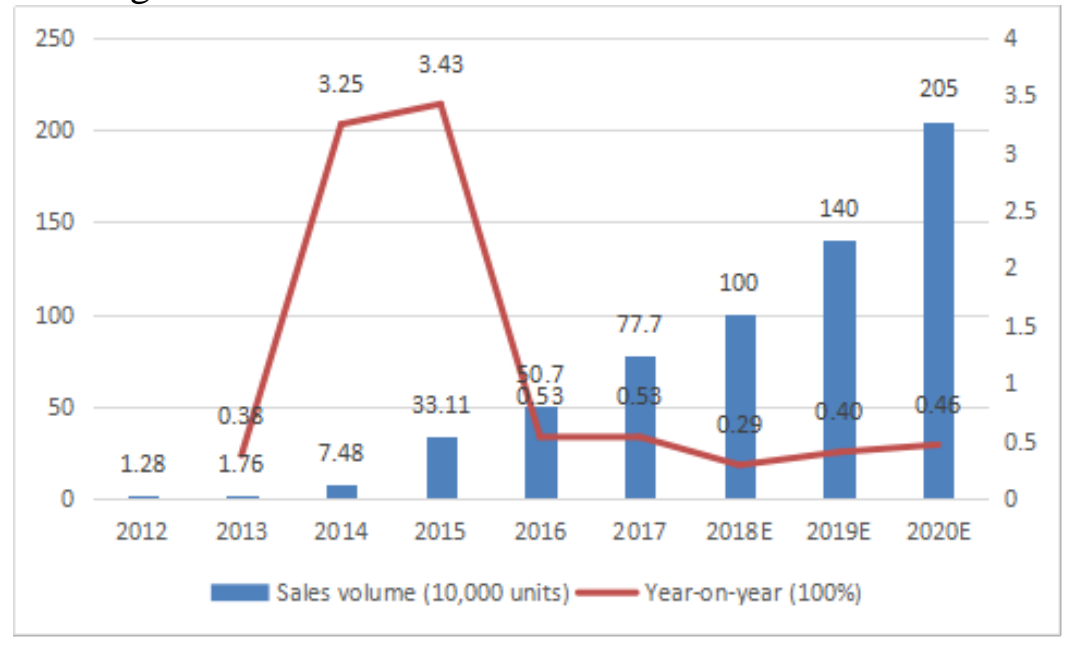

Figure 3 Forecast of sales and growth rate of new energy vehicles in 2018-2020

The definition and scope of new energy vehicles are defined in the "Regulations on the Administration of New Energy Vehicle Manufacturing Enterprises and Products" implemented on July 1, 2017. New energy vehicles are vehicles that use new power systems that are driven entirely or primarily by new energy sources, including plug-in hybrids (including extended-range) vehicles, pure electric vehicles, and fuel cell vehicles. 2016 is a year of development of the new energy automobile industry. It is not only the end of the "12th Five-Year" electric vehicle key special project, but also the starting year of the key special projects of the "13th Five-Year" National "New Energy Vehicle". The above-mentioned series of national policies mark that the new energy automobile industry will gradually get rid of financial subsidies, and the next step will rely mainly on core technologies for development. The Notice on the Financial Support Policy for the Promotion and Application of New Energy Vehicles in 2016-2020 stipulates that the subsidy standard for 2017-2018 will decrease by $20 \%$ on the basis of 2016 ; the subsidy standard for 
2019-2020 will decrease by $40 \%$ on the basis of 2016. The subsidy will be abolished in 2020, and the local financial subsidy must not exceed $50 \%$ of the central bicycle subsidy. The new energy auto industry will move from a "policy-driven market" to a "policy and market-driven market". As the ultimate driving force of consumers in the new energy automobile industry, the research on the factors influencing consumer purchase has high theoretical value and economic value.

\section{Questionnaire process}

The survey is aimed at the majority of the citizens of Zhejiang Province, the most dynamic and most influential province in China, including: 4S shop marketers, car maintenance personnel, driving school students and graduating college students. It mainly uses online questionnaires and on-site questionnaires. From June 1st to August 25th, 2018, a total of 1020 paper questionnaires were distributed, and 1002 valid questionnaires were collected. The online questionnaire collected 2059 valid questionnaires and a total of 2013 valid questionnaires were obtained.

\section{Analyzing results by survey}

Through the collation and analysis of domestic and foreign literature on the factors affecting the purchase of new energy vehicles, combined with the actual situation of Zhejiang Province, the province with the strongest purchasing power of Chinese residents, the authors from personal attributes, product attributes, policy attributes, market attributes and society. Five dimensions of the property, a questionnaire on the factors affecting the purchase of new energy vehicles in Zhejiang Province was formulated and an investigation was conducted.

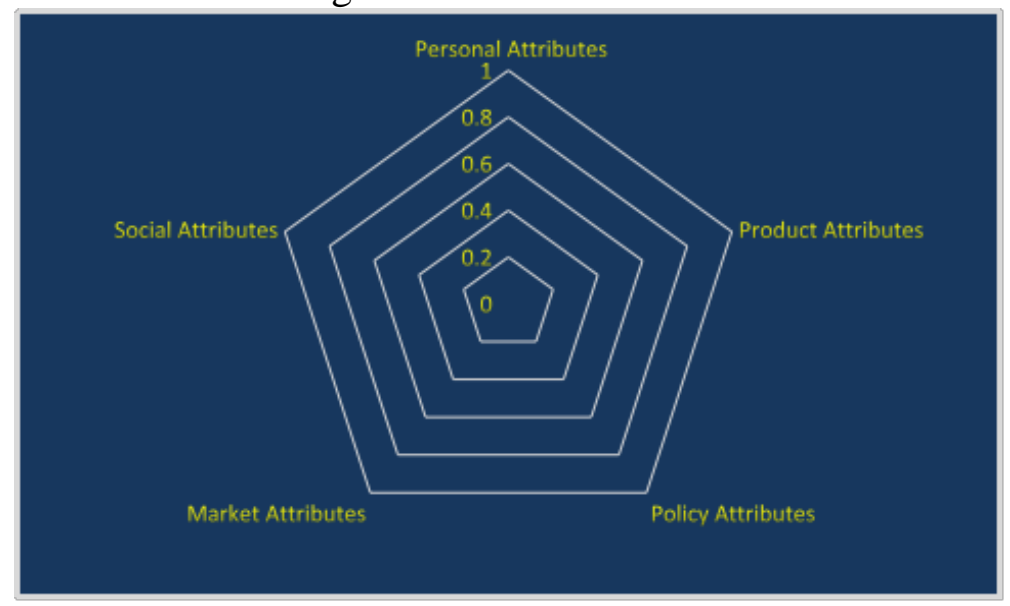

Figure 4 Five-dimensional analysis of factors affecting consumer purchases of new energy vehicles

\subsection{Personal Attributes}

Through the study of personal attribute dimension, we can understand the awareness and preference of Zhejiang residents for new energy vehicles, and summarize the characteristics of groups with high awareness and good preference for new energy vehicles.

The basic characteristics of the respondents in the questionnaire include: gender, age, education, occupation, income, and the basic characteristics of the sample data are shown in Figure 5. The purpose of the basic feature analysis is to accurately grasp the group characteristics of the new energy vehicle consumers. Accurately capture potential consumer groups. 

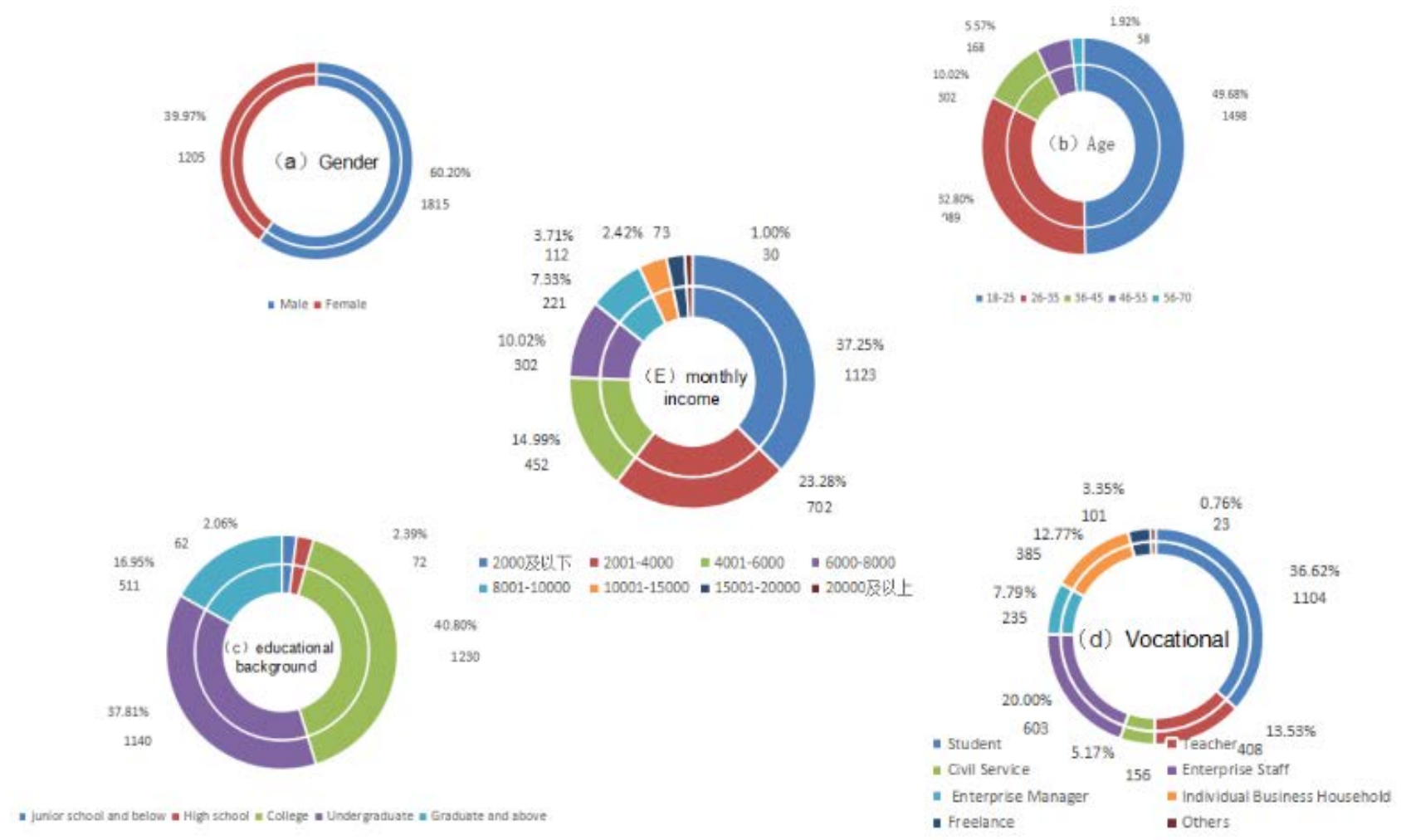

Figure 5 Basic feature distribution statistics of sample data

In the survey, we found that $86.3 \%$ of people have heard of new energy vehicles, $7.1 \%$ have not heard of them, $4.5 \%$ know about new energy vehicles, and only $2.1 \%$ know very well. It can be seen that the public's awareness of new energy vehicles has increased significantly, but the specific situation is not very well understood. At the same time, citizens have a strong desire to buy new energy vehicles, and $73.9 \%$ of them will consider new energy vehicles when they purchase cars in the future. The number of electric vehicles in Zhejiang Province has exceeded 100,000, reaching 138,745. The application fields include public transportation, rental, official business, special-purpose vehicles, leasing and private. The large-scale promotion and application of electric vehicles has begun.

\subsection{Product Attributes}

As a new thing, new energy vehicles will have different opinions and different considerations. Through this survey, we can better understand the needs of consumers. As can be seen in Figure 6(A), the current high price of new energy vehicles is also an important factor hindering consumer purchases. As can be seen in Figure 6(B), the results of the survey are in line with local consumption levels. As can be seen in Figure 6(C), as the level of appreciation of people continues to increase, the appearance requirements for new energy vehicles are also increasing. As can be seen in Figure 6(D), for product performance, consumers are more concerned with safety factor, number of failures, service life and energy consumption. 


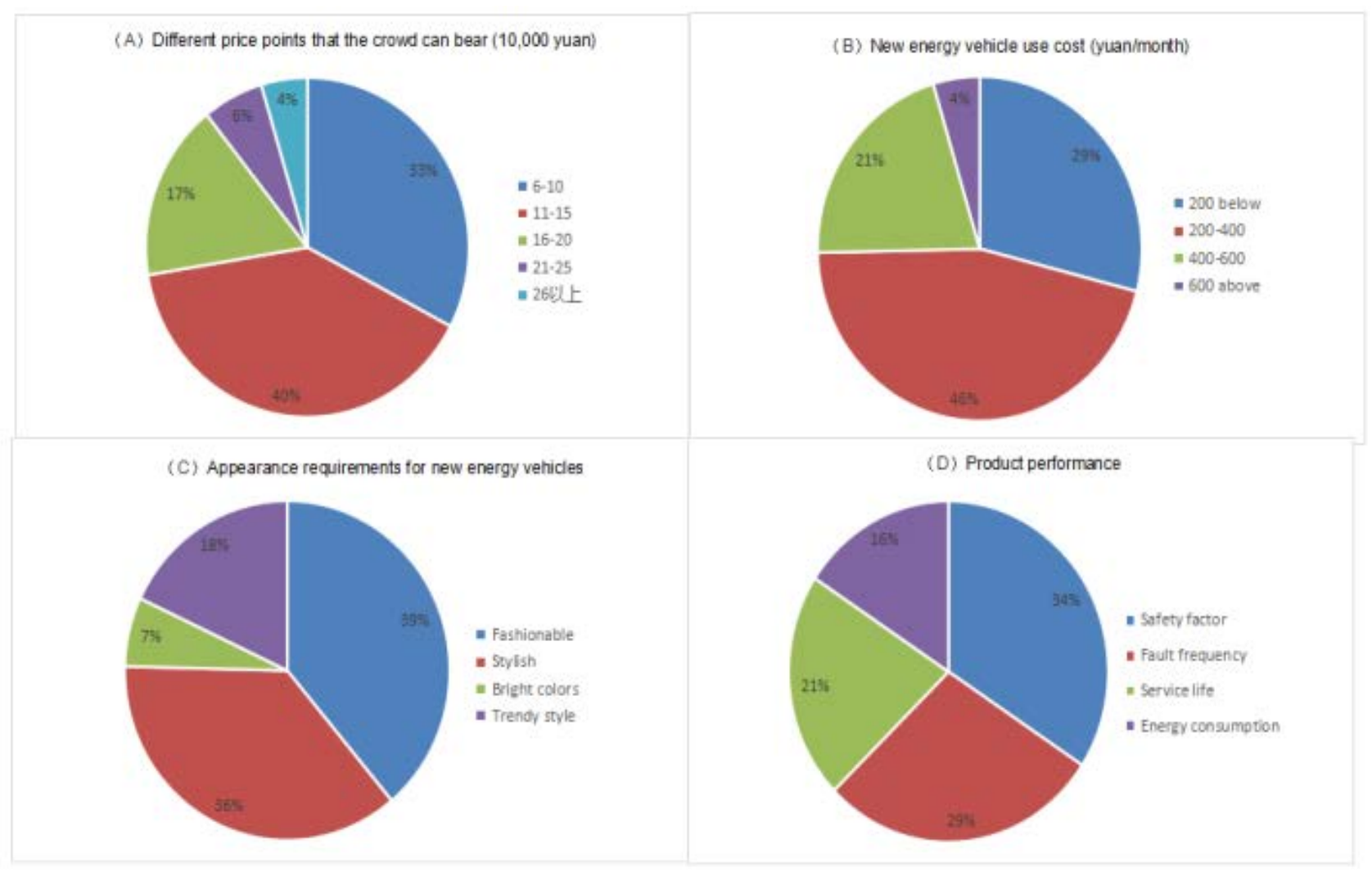

Figure 6 New energy vehicle product attributes that consumers care about

\subsection{Policy Attributes}

Supporting the development of new energy vehicles from national and local policy trends is mainly reflected in the state's subsidies for the mileage of new energy vehicles. People pay attention to new energy vehicles, but also focus on the above two points. Of course, in addition to the above two points, the charging pile layout, vehicle preservation value is also a common concern. Because according to the development of new energy vehicles today, the number of charging piles in the city can basically meet the charging needs of everyone, but there will still be many new energy owners who can't find local charging.

From the analysis of the relevant data intercepted in the 2018 car hedging rate analysis report, in the new energy vehicles with a cruising range of less than 250 kilometers, the average annual rate of the new car in the first year has dropped to only about 30\%, such a hedge ratio It is very difficult for the owner to accept. The value of the new energy vehicle's hedging rate is lower than that of the fuel vehicle. In fact, the battery loss of the vehicle is actually greater than the fuel consumption of the fuel vehicle, and the battery of the new energy vehicle is replaced after a certain period of use. The price is also much more expensive than the maintenance of the fuel car. If we look at the long-term development trend, the vehicle's hedging rate will be an important bottleneck for the development of new energy vehicles. For this, the author suggests that the country can also introduce relevant subsidy policies for new energy used cars like new car subsidies. ? If there is a subsidy policy to solve the worries of the owners, perhaps the acceptance of new energy vehicles will be further improved. 


\subsection{Market Attributes}

On September 17, 2018, the China Automobile Association and the China Federation of Trade Unions released the production and sales of new energy vehicles in August and the sales of new energy passenger vehicles. In August, sales of new energy passenger vehicles increased by 62\% year-on-year and 19\% quarter-on-quarter. In the case of automobile production in August fell by $4.4 \%$ and $2.1 \%$, sales volume decreased by $3.8 \%$ year-on-year and $11.3 \%$ quarter-on-quarter, the production and sales volume of new energy vehicles achieved steady growth. From January to August, the cumulative production and sales volume of new energy vehicles reached 607,000 and 601,000 respectively, up $75.4 \%$ and $88.0 \%$ respectively, maintaining a high growth trend.

\subsection{Social Attributes}

People live in society, and consumer behavior is affected by many social factors, such as differences in social culture, related groups, and advertising effects. The statistics on the distribution of social factors are shown in Table 1. It can be seen that the four items of the survey, each of which has a majority of people will be affected by the external environment.

Table 1 Social attribute factors of new energy vehicle purchase

\begin{tabular}{|lccccc|}
\hline & $\begin{array}{c}\text { Very much } \\
\text { agree }\end{array}$ & Agree & Uncertain Not agreeing & $\begin{array}{c}\text { Strongly } \\
\text { disagree }\end{array}$ \\
$\begin{array}{c}\text { The society strongly promotes } \\
\text { the concept of environmental } \\
\begin{array}{c}\text { protection } \\
\text { Progress and development of }\end{array}\end{array}$ & $56.21 \%$ & $28.56 \%$ & $11.32 \%$ & $2.89 \%$ & $1.02 \%$ \\
$\begin{array}{c}\text { new energy vehicle technology } \\
\text { People's own awareness of new } \\
\text { energy vehicles }\end{array}$ & $48.25 \%$ & $39.06 \%$ & $8.11 \%$ & $2.46 \%$ & $2.12 \%$ \\
$\begin{array}{c}\text { Affected by friends and relatives } \\
\text { around }\end{array}$ & $38.12 \%$ & $25.79 \%$ & $28.98 \%$ & $5.00 \%$ & $2.11 \%$ \\
\hline
\end{tabular}

\section{Conclusions and Recommendations}

\subsection{Conclusions}

Through investigation and sample cross-analysis, we can get the following conclusions: (1) People between the ages of 18-40 are more willing to understand new energy vehicles, and their desire to purchase is stronger; (2) With the growth of academic qualifications, new energy sources The understanding of automobiles will also increase; (3) citizens generally have doubts about the technical reliability, subsequent charging and maintenance costs of new energy vehicles; (4) the price of new energy vehicles compared with traditional vehicles. High and low holding rate; (5) About $40 \%$ of people will be affected by the social environment when buying a car.

\subsection{Recommendations}

(1) To play the role of demonstration in the public domain of new energy vehicles. In the city's 
public transportation sector, the first to use new energy vehicles, such as: buses, taxis, sightseeing vehicles, etc., and prominently posted new energy vehicle signs on these vehicles; the widespread use of new energy vehicles will be for consumers. The impact of subtle influences helps to break consumer concerns about new energy vehicles.

(2) Give full consideration to the needs of consumers. The cruising range of new energy vehicles and the convenience of charging facilities are important factors influencing consumers' purchases. In addition, after-sales links are also more concerned by consumers, after-sales links include: after-sales maintenance, maintenance, insurance, battery recycling and so on.

(3) Increase the promotion and promotion of new energy vehicles. Make full use of modern technology, increase publicity and promotion, and publicize through various channels such as print media, online media, TV broadcast media, auto show and factory sales. The promotion includes mature technology, supporting facilities, after-sales service, related policies, national standards of the industry, and so on.

\section{References}

[1] Jiang Aihua, Sheng Xiangyu. Influencing Factors and Guidance Policy of Consumers' Willingness to Buy New Energy Vehicles [J].Financial science, 2017(5).

[2] Yang Jie.Study on the Factors Affecting the Purchase of New Energy Vehicle Consumers [J].Shanghai Management Science, 2016(3).

[3] Lu Yunhui. Research on Drivers of New Energy Vehicle Consumers [J].Low-carbon World, 2017(19).

[4] Haichen.2017 China Six Cities New Energy Vehicle Consumer Survey [J].Cars and accessories, 2017(33). 